To appear in the Journal of Building Performance Simulation

Vol. 00, No. 00, Month 20XX, 1-25

\title{
Validated Air Handling Unit Model using Indirect Evaporative Cooling
}

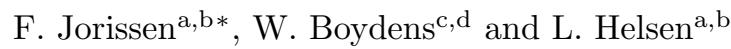 \\ ${ }^{a}$ University of Leuven, Celestijnenlaan 300 - bus 2421, 3000 Leuven, Belgium; ${ }^{b}$ EnergyVille, Thor Park \\ 8310, 3600 Genk, Belgium; ${ }^{c}$ Boydens Engineering, Noordkustlaan 10, 1702 Dilbeek, Belgium; ${ }^{d}$ University \\ of Ghent, St. Pietersnieuwstraat 33, 9000 Ghent, Belgium
}

(September 2016)

Keywords: Modelica; Air Handling Unit; Model; Indirect Evaporative Heat Exchanger

\begin{abstract}
This paper presents the validated Modelica model of a Menerga ${ }^{\mathrm{TM}}$ Adsolair ${ }^{\mathrm{TM}}$ type 58 Air Handling Unit (AHU). The unit consists of two fans, four dampers, three air filters and further allows heat recovery (including free cooling), indirect evaporative cooling and active cooling. The first principles model uses manufacturer data sheet information and optionally also measurement data to calibrate some parameters for increased accuracy. Model validation is based on measurement data and results in an average normalised absolute error for the electrical power consumption of approximately $1 \%$. A custom developed control strategy is compared with the measured performance of a proprietary controller. The model is available open source as part of the IDEAS Modelica library.
\end{abstract}

\section{Nomenclature}

\section{Acronyms}

AHU Air handling unit

COP Coefficient of performance

IEH Indirect evaporative heat exchanger

Indices

bot Bottom / supply air stream

con Condenser

dam Damper

eva Evaporator

fan Fan

fou Fouling

in Inlet stream

nom Nominal operating conditions

out Outlet stream

pum Evaporative cooling circulation pump

ref Refrigerant

set Set point

top Top / return air stream

wat Water evaporation or condensation

wb Wet bulb

*Corresponding author. Email: filip.jorissen@gmail.com 


\section{Symbols}

$\alpha \quad$ Fraction of dynamic pressure that is recovered as a static pressure increase when expanding the supply air bypass channel

$\Delta p_{i} \quad$ Static pressure drop of component i

$\Delta p_{\text {damBypBot }}$ Lumped static pressure drop of AHU components along the supply air bypass

$\Delta p_{\text {damBypTop }}$ Lumped static pressure drop of AHU components along the return air bypass

$\Delta p_{\text {damRecBot }}$ Lumped static pressure drop of AHU components along the supply air branch passing through the heat recovery unit

$\Delta p_{\text {damRecTop }}$ Lumped static pressure drop of AHU components along the return air branch passing through the heat recovery unit

$\dot{m}_{i} \quad$ Mass flow rate through component i

$\dot{m}_{\text {nom }}$ Nominal mass flow rate of the AHU of $4.69 \mathrm{~kg} \mathrm{~s}^{-1}$

$\dot{Q} \quad$ Heat flow rate

$\dot{Q}_{\max }$ Maximum heat flow rate for NTU method

$\dot{V} \quad$ Volumetric flow rate

$\epsilon \quad$ Heat exchanger effectivity

$\epsilon_{1 / 2} \quad$ Effectivity of one of the two segments of the heat recovery unit

$\eta_{f} \quad$ Hydraulic efficiency of the fan

$\eta_{m} \quad$ Mechanical efficiency of the motor, including frequency converter

$\phi \quad$ Relative humidity

$\rho_{\text {air }} \quad$ Air density

$\tau \quad$ Time constant of energy and mass dynamics

$\theta \quad$ Damper opening angle in degrees

a Equals true when evaporative cooling is enabled and false otherwise

$A_{i} \quad$ Frontal surface area of damper i

$B P F$ Bypass factor of evaporator

$c \quad$ Equals true when chiller is on and false otherwise

$C_{i} \quad$ Heat capacity rate

$c_{p} \quad$ Specific heat capacity at constant pressure

$G \quad$ Thermal conductivity

$h \quad$ Specific enthalpy

$k_{1} \quad$ Ratio of static pressure drop of fully opened damper and dynamic pressure in the damper

$k_{i} \quad$ Flow coefficient of component i

$k_{d a m, i}$ Fixed flow coefficient of fully opened damper

$k_{f i x, i}$ Fixed flow coefficient for pressure drop components in series with damper i

$k_{P I} \quad$ Damper PI controller gain

mod Modulation rate of chiller

$n_{i} \quad$ Fan speed at operation point i

$N T U$ Number of transfer units

$o \quad$ AHU status: on or off

$p \quad$ Thermodynamic pressure

$P_{0} \quad$ Zero-load active power consumption of AHU

$P_{i} \quad$ Active power consumption

$P_{e l} \quad$ Total active power use of the AHU

$P L F \quad$ Part load factor of chiller

$\operatorname{pre}(x)$ Value of $\mathrm{x}$ during previous time step

$r \quad$ Gas constant of dry air

$T \quad$ Dry bulb temperature

$U A_{\text {off }}$ Total thermal conductivity of heat recovery unit when adiabatic cooling is disabled

$U A_{o n}$ Total thermal conductivity of heat recovery unit when adiabatic cooling is enabled

$v \quad$ Specific volume

$X \quad$ Absolute humidity 


\section{$y_{i} \quad$ Control signal $(\in[0,1])$ of damper i \\ $y_{P I} \quad$ Damper PI controller output}

\section{Introduction}

Heating Ventilation and Air Conditioning (HVAC) systems use approximately $20 \%$ of the primary energy (Pérez and Ortiz and Pout 2008). Research in the fields of advanced controls and fault detection and diagnosis relies on validated computer models of HVAC components in order to reduce the energy use of these components, or the systems in which they are used. A major source of energy use in buildings is the Air Handling Unit (AHU), primarily for the fans and air conditioning components.

However, few validated models of AHU are available in the literature. ASHRAE RP- 825 presents models for many AHU components, but does not provide a validation of the integrated system model. This work was extended by Li and Wen (2010) with a new coil valve model and a new fan energy model. Nassif and Moujaes and Zaheeruddin (2008) present a self-tuning approach for dynamic HVAC models, which was applied to an AHU model. TRNSYS (Klein 2010) 16 type 334 is a simple air handling unit model with adiabatic pre-cooling, but has not been validated. Similarly EnergyPlus (Crawley et al. 2001) contains many component models and some unitary models but does not present a validated AHU with indirect evaporative cooling (EnergyPlus Documentation 2016). A detailed research overview is provided by Li et al. (2014), who suggest that many component models have been published in literature but further indicate that only few validated AHU models exist. For detailed building energy simulation models that are used to compute or optimise HVAC energy use, such models are however required.

This paper therefore presents a validated model of an AHU that computes the electrical power consumption and thermodynamic properties of the outlet air flows. To allow this, the internal pressure drop and mass flow rates are also computed. The model uses physically interpretable equations and parameters. Furthermore it can be calibrated using manufacturer data sheet information that is commonly available. Further calibration has been performed based on measurement data to estimate the values of some parameters that do not appear in the data sheet.

The model is implemented in Modelica and published in the IDEAS Modelica library (Baetens et al. 2015). The implementation of all equations is therefore available open-source and the model may be copied and changed for other purposes, for instance serving as a template or example for similar AHU models. Submodels like the indirect evaporative heat exchanger may also be reused in other models or as a stand-alone component. The model could also be altered to test the performance of new designs or new control strategies. The model itself may even be used as part of the control strategy of the AHU by exporting it using the FMI standard. Since Modelica is an equation-based language gradient-based optimisation methods could even be used in such a controller.

Furthermore this paper demonstrates that Modelica may be used to perform detailed simulations of AHU models, including their control strategies. Since the model contains fast dynamics, table interpolations, piecewise functions, pyschrometric calculations, non-linear algebraic loops and discrete equations, it is a relatively complex HVAC model, suggesting that HVAC systems in general may be simulated using Modelica.

The paper is organised as follows. Section 2 describes the AHU functionality that will be modelled and section 3 describes the model equations. Section 4 describes some implementation details and section 5 explains the model calibration. Section 6 contains the model validation and section 7 presents conclusions. 


\section{System description}

This paper presents the validated model of a Menerga ${ }^{\mathrm{TM}}$ Adsolair ${ }^{\mathrm{TM}}$ type 58 Air Handling Unit (AHU). Figures 1a - 1c show the layout of this AHU during its three operation modes. The AHU internal controller determines the operation mode such that the dry bulb supply temperature set point is obtained. The supply air humidity is not controlled in this model. The AHU has two air streams that do not exchange mass. One variable speed fan for each air stream forces the flow through a heat recovery unit or through a parallel bypass. The indirect evaporative heat exchanger (IEH) is shown in the middle of the figure. The IEH has two inlets and two outlets and consists of two cross flow heat exchangers connected in series. The two air streams exchange heat, but not mass. Water can be evaporated adiabatically in the return air stream by sprinkling water on the heat exchanger plates. Excess water is collected at the bottom of the IEH and is then reused. The water reservoir is flushed occasionally, a process which is not modelled. A modulating vapour compression cycle chiller allows further cooling of the supply air stream. The chiller extracts heat from the evaporator at the outlet of the indirect evaporative heat exchanger's supply air stream and rejects heat through the condenser into the return air stream. A heating coil is installed at the supply air outlet of the AHU and a cooling coil is installed at the supply air inlet of the AHU. The AHU further contains five dampers. Four opposed blade dampers are used to control the air fraction that passes through the two bypasses. The fifth damper is always closed in the measurement data set and is therefore disregarded in this model. The two variable speed fans are controlled such that AHU supply and return air duct pressure set points are obtained. The AHU contains three air filters, one at the inlet and outlet of the supply air stream and one at the inlet of the return air stream.

Although the AHU control strategy is proprietary and unknown to the authors, measurements indicate that three main operation modes exist: 1) heat recovery mode, 2) indirect evaporative cooling mode 3) active cooling mode. Proprietary heuristics determine what mode is selected.

Figure 1a illustrates the heat recovery mode. In this mode the four dampers are used to control the bypass air flow rates such that the supply temperature set point is obtained. Active cooling and indirect evaporative cooling are disabled. Figure 1b depicts the second mode. The dampers are again used to track the supply temperature set point but additional cooling is provided by the indirect evaporative heat exchanger. The active chiller is disabled. Figure 1c illustrates the active cooling mode. Bypass dampers are closed. The indirect evaporative heat exchanger may or may not be enabled depending on heuristics. The supply temperature set point is tracked by controlling the modulation rate of the active chiller.

\section{Model description}

A schematic of the AHU model inputs and outputs is shown in Figure 2. The model control inputs are its status $o$ : on or off, the dry bulb outlet temperature set point of the supply air $T_{\text {set }}$ and the supply and return air duct pressure set points relative to the ambient pressure $\Delta p_{\text {set }}$. $T_{\text {set }}$ is further referred to as the supply temperature set point. The model computes the electrical power used by the AHU $P_{e l}$ and the thermodynamic states (pressure, enthalpy and absolute humidity) of the two air streams exiting the AHU. It also consists of a pressure drop model that allows to compute the internal pressure drops of the unit.

The model is implemented using the Modelica language. It is partly composed of models from the Annex60 library (Wetter et al. 2015). For these components only the relevant equations are elaborated in the following sections. This section sequentially describes the pressure drop model, thermodynamic model, the controller model and the electrical power consumption model. 


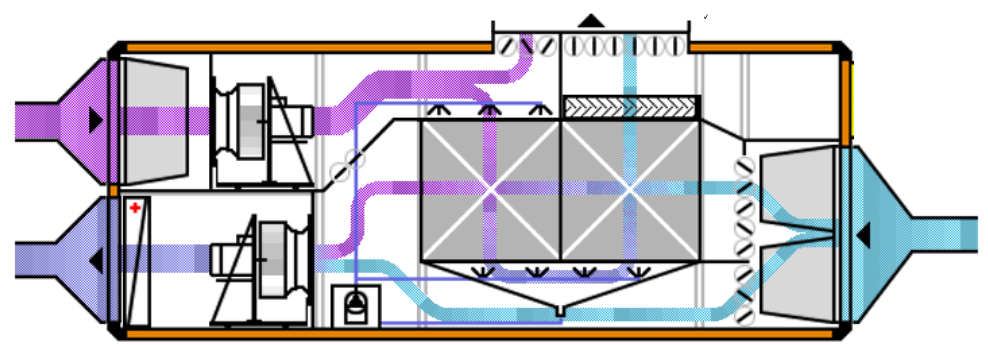

(a) Heat recovery mode (includes free cooling). Bypasses are used to track the supply temperature set point. Active and indirect evaporative cooling are disabled.

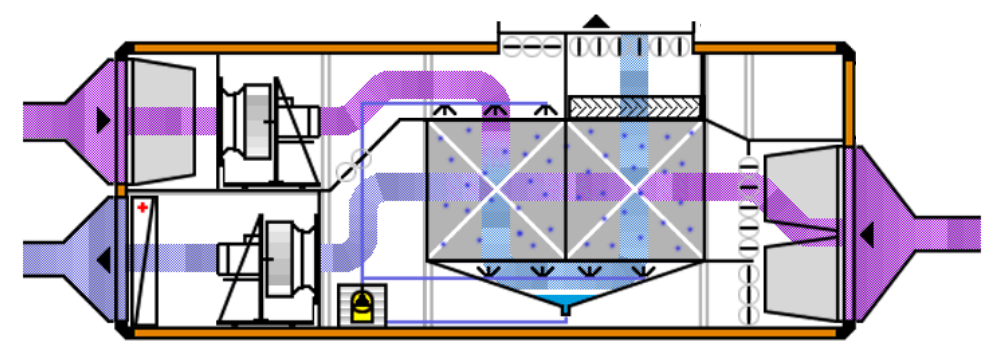

(b) Indirect evaporative cooling mode. Indirect evaporative cooling is enabled by spraying water inside of the heat recovery unit. Bypasses are used to track the supply temperature set point. Active cooling is disabled.

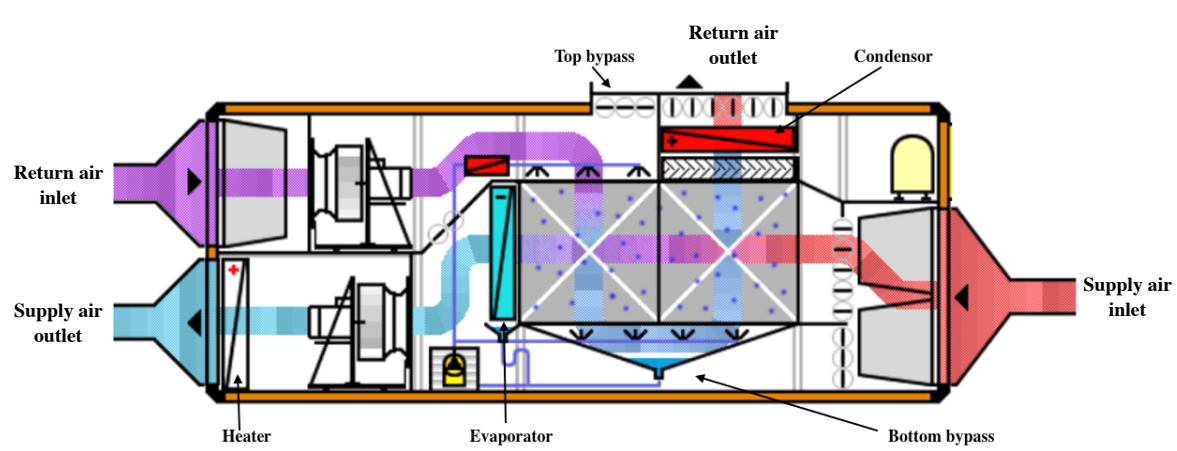

(c) Active cooling mode. Bypasses are closed. The air-to-air heat pump extracts heat from the indirect evaporative heat exchanger (IEH) supply air outlet and rejects it into the IEH return air outlet. The refrigerant subcooler indicated in red at the top left of the IEH was not installed in the studied unit.

Figure 1.: Schematics of the AHU system operation and air flows during its three operation modes. System components are indicated in (c). Edited from Menerga ${ }^{\mathrm{TM}}$ Belgium.

\subsection{Pressure drop model}

A flow network model computes the mass flow rates and the pressure drops inside the AHU needed to compute the electrical power consumption and thermodynamic properties. The AHU structure was shown in Section 2. We here explain how its various components are modelled.

\subsubsection{Model structure}

Most AHU components cause pressure drops, but since many of these components are connected in series, their pressure drops are lumped for computational reasons (Jorissen and Wetter and Helsen 2015). Table 1 lists the nominal pressure drops for all components that are listed in the data sheet. 


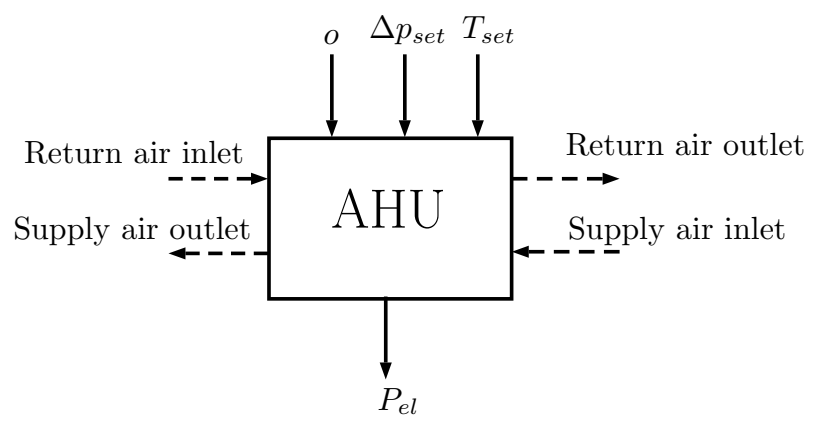

Figure 2.: Schematic overview of the AHU model. Full lines indicate real input or output variables. $\Delta p_{\text {set }}$ are two pressure set points for the supply and return air ducts. $T_{\text {set }}$ is the dry bulb temperature set point of the supply air. $o$ is a boolean variable that indicates whether the AHU is on or off. $P_{e l}$ is the total active (electrical) power consumption of the AHU. Dashed lines indicate air flows, for which the model contains variables for mass flow rate and thermodynamic properties.

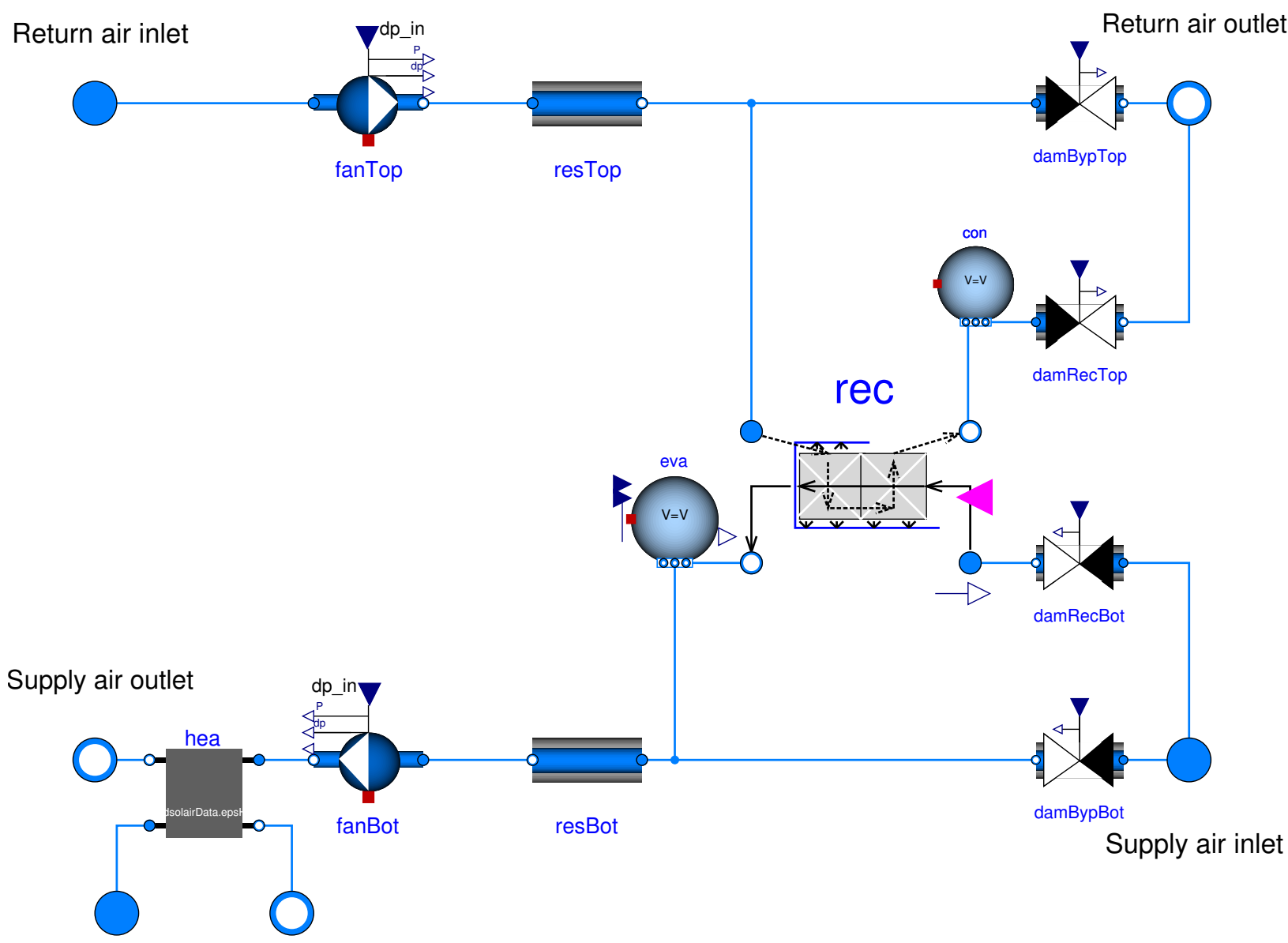

Figure 3.: Main model structure indicating air flows and pressure drop components: fans fanTop and fanBot, dampers damByp Top, damRecTop, damRecBot, damBypBot, indirect evaporative heat recovery unit rec, condensor con, heating coil hea and evaporator eva.

Figure 3 is a schematic representation of the pressure drop model. The supply air stream enters the model at the bottom right, flows along the blue lines, through various components and leaves the model at the bottom left. Similarly, the return air stream enters the model at the top left and leaves the model at the top right. Both air flow streams have a dedicated fan, fanTop and fanBot, which increase the static air pressure between the fan inlet and outlet by respectively $\Delta p_{\text {fan,top }}$ and $\Delta p_{\text {fan,bot }}$. Furthermore there are two pressure drop components resTop and resBot, which 
Table 1.: Symbols and data sheet values for nominal pressure drops corresponding to a nominal flow rate of $14200 \mathrm{~m}^{3} \mathrm{~h}^{-1}$. Final pressure drops indicate the pressure drops when filters must be replaced.

\begin{tabular}{llrr}
\hline & Symbol & Nominal pressure drop & Final pressure drop \\
\hline Heating coil & $\Delta p_{\text {nom, hea }}$ & 33 & NA \\
Cooling coil & $\Delta p_{\text {nom,coo }}$ & 55 & NA \\
Supply inlet filter & $\Delta p_{\text {nom, } 1}$ & 33 & 250 \\
Supply outlet filter & $\Delta p_{\text {nom, }, 2}$ & 70 & 250 \\
Return inlet filter & $\Delta p_{\text {nom, } 33}$ & 46 & 250 \\
Supply heat recovery & $\Delta p_{\text {nom,rec,bot }}$ & 195 & NA \\
Return heat recovery (RHC) & $\Delta p_{\text {nom,rec,top }}$ & 211 & NA \\
RHC with evaporative cooling & $\Delta p_{\text {nom,rec,top,eva }}$ & 271 & NA \\
Condenser & $\Delta p_{\text {nom,con }}$ & 76 & NA \\
Evaporator & $\Delta p_{\text {nom,eva }}$ & 63 & NA \\
\hline
\end{tabular}

are lumped pressure drop models for various filters and heat exchangers along the flow path and that cause a pressure drop $\Delta p_{\text {top }}$ and $\Delta p_{\text {bot }}$. The air streams are split in two parts by four dampers damBypTop, damRecTop, damRecBot, damBypBot that cause pressure drops $\Delta p_{i}$ and which have control signals $y_{i}$ for $i \in\{\operatorname{damBypTop}$, damRecTop, damRecBot,damBypBot $\}$. Component models of the heating coil hea, evaporator eva and condenser con do not create a pressure drop directly, since their pressure drop calculations are added to components that are in series with the respective component. The cooling coil is not indicated on the figure since its control strategy is not considered in this work due to a lack of measurement data for this component. Its pressure drop is however taken into account since the component is physically present in the unit.

\subsubsection{Model equations}

3.1.2.1. Pressure drop equations. Dampers (damBypTop, damRecTop, damRecBot and damBypBot), and lumped pressure drop components resTop and resBot each represent a pressure drop equation where

$$
\Delta p_{i}=\left(\frac{\dot{m}_{i}}{k_{i}}\right)^{2}
$$

with $\Delta p_{i}$ the pressure drop over component $i, \dot{m}_{i}$ the mass flow rate through component $i$ and $k_{i}$ a flow coefficient. The influence of the air density is assumed to be negligible in the model used from (Wetter et al. 2015).

Fixed flow coefficient components. For resTop and resBot $k$ is computed using nominal values for $\dot{m}$ and $\Delta p$ in Equation (1) such that

$$
k_{i}=\frac{\dot{m}_{\text {nom }}}{\sqrt{\Delta p_{\text {nom }, i}}}
$$

where $\dot{m}_{n o m}=4.69 \mathrm{~kg} \mathrm{~s}^{-1}$ is the nominal mass flow rate of the AHU and $\Delta p_{n o m, i}$ the nominal pressure drop of component $i$ as shown in Table 1 . 
Based on the description in Section 2 we find nominal pressure drops $\Delta p_{n o m, t o p}$ and $\Delta p_{n o m, b o t}$ in Equations (3)-(4) for respectively resTop and resBot.

$$
\begin{aligned}
& \Delta p_{\text {nom }, \text { top }}=\Delta p_{\text {nom }, f 3}+\Delta p_{\text {fou }, f 3} \\
& \Delta p_{\text {nom }, \text { bot }}=\Delta p_{\text {nom }, f 1}+\Delta p_{\text {nom }, f 2}+\Delta p_{\text {nom }, \text { hea }}+\Delta p_{\text {nom }, \text { coo }}+\Delta p_{f o u, f 12}
\end{aligned}
$$

These expressions include variables $\Delta p_{f o u, f 12}$ and $\Delta p_{f o u, f 3}$ that incorporate the pressure drop caused by fouling of the top and bottom filters.

Variable flow coefficient components. For $i \in$ damBypTop, damBypBot, damRecBot and damRecTop $k_{i}$ is computed as the series connection of a 'fixed' pressure drop such as in Equation 1 and a controllable pressure drop from the damper. This results in Equation 5

$$
k_{i}=\sqrt{\frac{1}{\frac{1}{k_{f i x, i}^{2}}+\frac{1}{\left(k_{\text {dam }, i} \cdot f\left(y_{i}\right)\right)^{2}}}}
$$

where $k_{f i x, i}$ is the flow coefficient of the fixed pressure drop components in series with the damper, $k_{d a m, i}$ is the $k$ value of fully open damper and $f\left(y_{i}\right) \in[0,1]$ is a damper opening characteristic taken from chapter 7, Figure 13B in ASHRAE Handbook (2009), which is implemented using the third degree polynomial fit presented by Equation (6).

$$
f\left(y_{i}\right)=0.582675 \cdot y_{i}^{3}+0.222823 \cdot y_{i}^{2}+0.192212 \cdot y_{i}
$$

A logarithmic expression, as proposed by Legg (1986), was not used since this is only defined for opening angles $15^{\circ}<\theta<65^{\circ}$ and yielded worse results in the validation. Parameter $k_{d a m, i}$ is computed assuming that the damper pressure drop is a fraction of the dynamic pressure drop when $y_{i}=1$ such that

$$
k_{d a m, i}=k_{1} \cdot \sqrt{2 \cdot \rho_{a i r}} \cdot A_{i}
$$

with $A_{i}$ the frontal surface area of the damper, $\rho_{\text {air }}$ the nominal air density and $k_{1}$ a parameter that specifies the ratio of the damper pressure drop when fully opened to the dynamic pressure.

Bypass pressure drop. In the bypass channels a significant flow contraction occurs, which leads to a flow speed increase and corresponding dynamic pressure increase. For the top channel the contraction and expansion, which occur while passing through the damper, are abrupt, so it is assumed that the dynamic pressure is not recovered. A pressure drop is therefore computed using Equation (7), where the cross section area of the top damper equals $A_{i}=0.408 \mathrm{~m}^{2}$ and $k_{1}=1$.

In the bottom bypass channel the flow first contracts and then expands through a channel formed by one horizontal plate and two plates that form an angle of about $30^{\circ}$ with the horizontal plate. The channel contains a number of pipes that obstruct the flow. Due to the gradual contraction and expansion we assume that a fraction $\alpha$ of the dynamic pressure is recovered by introducing a pressure drop Equation (2) with $k_{i}$ determined by Equation (7), where $A_{i}=0.255 \mathrm{~m}^{2}$ is the cross section area of the bottom channel contraction and $k_{1}=1-\alpha$.

IEH pressure drop. For the heat recovery channels $k_{f i x, i}$ is computed using Equation (2) with

$$
\begin{aligned}
& \Delta p_{\text {nom }, \text { fix }, \text { damRecBot }}=\Delta p_{\text {nom }, \text { eva }}+\Delta p_{\text {nom }, \text { rec }, \text { bot }} \\
& \Delta p_{\text {nom }, \text { fix,damRecTop }}=\Delta p_{\text {nom }, \text { con }}+\text { if } a \text { then } \Delta p_{\text {nom,rec }, \text { top }, \text { eva }} \text { else } \Delta p_{\text {nom }, \text { rec }, \text { top }}
\end{aligned}
$$


Table 2.: Interpolation points that were used to define the fan head and efficiency curves. $\Delta p_{1}$ and $\eta_{f}$ are respectively the static fan head and fan hydraulic efficiency corresponding to volumetric flow rate $\dot{V}_{1}$ at a speed of $1800 \mathrm{rpm}$.

\begin{tabular}{llccccccccc}
\hline$\dot{V}_{1}$ & {$\left[\mathrm{~m}^{3} \mathrm{~s}^{-1}\right]$} & 1.5 & 2 & 2.5 & 3 & 3.5 & 4 & 4.5 & 5 & 5.5 \\
\hline$h\left(\dot{V}_{1}\right)=\Delta p_{1}$ & {$[\mathrm{~Pa}]$} & 1385 & 1357 & 1317 & 1260 & 1176 & 1055 & 916 & 757 & 568 \\
$g\left(\dot{V}_{1}\right)=\eta_{f}$ & {$[-]$} & 0.452 & 0.527 & 0.590 & 0.687 & 0.723 & 0.700 & 0.720 & 0.703 & 0.620 \\
\hline
\end{tabular}

with $a$ a boolean variable that is true when the evaporative cooling function is enabled and false otherwise.

3.1.2.2. Fan equations. FanTop and fanBot ensure that the duct pressure set points $\Delta p_{\text {set }}$ are obtained. Since internal pressure drops in the AHU must be compensated, the pressure gain over the fans equals

$$
\begin{aligned}
& \Delta p_{\text {fan }, \text { top }}=\Delta p_{\text {set }, \text { top }}+\Delta p_{\text {top }}+\Delta p_{\text {damBypTop }} \\
& \Delta p_{\text {fan }, \text { bot }}=\Delta p_{\text {set }, \text { bot }}+\Delta p_{\text {bot }}+\Delta p_{\text {damBypBot }} .
\end{aligned}
$$

This assumes that the return air outlet and supply air inlet are at ambient pressure.

The electrical power consumption of the fan motor equals

$$
P_{f a n, i}=\frac{\dot{m} \cdot \Delta p_{f a n, i}}{\rho_{a i r} \cdot \eta_{f} \cdot \eta_{m}}
$$

with $\rho_{\text {air }}$ the density of the fluid at the fan inlet. The motor and integrated frequency converter efficiency $\eta_{m}$ is assumed to be constant and equal to the data sheet nominal value of $88.7 \%$. The fan efficiency is computed using the Annex 60 library (Wetter et al. 2015; Wetter 2013) fan model, which implements affinity laws such that $\eta_{f}$ satisfies

$$
\begin{aligned}
\eta_{f} & =\eta\left(\dot{V}_{1}\right) \\
\Delta p_{1} & =H\left(\dot{V}_{1}\right) \\
\frac{\dot{V}_{1}}{\dot{V}_{\text {fan }, i}} & =\frac{n_{1}}{n} \\
\frac{\Delta p_{1}}{\Delta p_{\text {fan }, i}} & =\left(\frac{n_{1}}{n}\right)^{2}
\end{aligned}
$$

where $H(\cdot)$ is a function that returns the fan head $\Delta p_{1}$ as a function of the fan volumetric flow rate $\dot{V}=\frac{\dot{m}}{\rho_{\text {air }}}$ for a fan speed of $n_{1}=1800 \mathrm{rpm}, \eta(\cdot)$ is a function that returns the fan efficiency as a function of the flow rate for the same fan speed $n_{1}$ and $n$ is the fan speed at operation point $\left(\Delta p_{f a n, i}, \dot{V}_{f a n, i}\right)$.

Functions $H(\cdot)$ and $\eta(\cdot)$ are implemented using piecewise trajectories from Table 2 that are interpolated using a cubic Hermite spline interpolation (Späth 1995). The trajectories are obtained from the data sheet of the $630 \mathrm{~mm}$ radial fans.

3.1.2.3. Tuning variables. The pressure drops caused by the unknown degree of filter fouling $\Delta p_{f o u, f 12}$ and $\Delta p_{f o u, f 3}$, the pressure recovery factor $\alpha$ and $k_{1}$ are unknown. These variables will 
be tuned using measurement data.

\section{2. $\quad$ Thermodynamic model indirect evaporative heat exchanger}

\subsubsection{Model structure}

The model needs to define four variables for each of the two outlet streams: the pressure, the mass flow rate, the specific enthalpy and the absolute humidity. The four first variables are trivial since 1) the inlet pressures equal the outlet pressures since pressure drop calculations are made outside of this component, as part of the damper models and 2) mass is conserved.

Four other variables still need to be defined: the outlet specific enthalpies and absolute humidity, or equivalently, the outlet temperature $T_{\text {out,top }}$ and $T_{\text {out,bot }}$ and absolute humidity $X_{\text {out,top }}$ and $X_{\text {out }, \text { bot }}$. The equations defining these variables are explained in Subsection 3.2.2.

\subsubsection{Model equations}

Consider $X(\phi, T)$ to be a function that computes that absolute humidity ( $\mathrm{kg}$ water $/ \mathrm{kg}$ of total air) as a function of the relative humidity $\phi$ and dry bulb temperature $T$. Similarly $h(X, T)$ is a function that computes the specific enthalpy of moist air with an absolute humidity $X$ and dry bulb temperature $T . T(X, h)$ is the inverse of $h(X, T) . T_{w b}(X, T)$ returns the wet bulb temperature for dry bulb temperature $T$ and absolute humidity $X$ and finally, $h_{w a t}(T)$ returns the specific enthalpy of pure water with temperature $T$. The implementation of these functions is based on (Wetter et al. 2015), which assumes constant heat capacities.

3.2.2.1. Heat transfer computations. The outlet temperatures are computed using the effectiveness-NTU method (Kays and London 1984):

$$
\dot{Q}=\dot{Q}_{\max } \cdot \epsilon
$$

where $\mathrm{Q}$ is the total heat flow rate from the bottom air stream to the top air stream, $\dot{Q}_{\max }$ is the maximum heat flow rate and $\epsilon$ is the heat exchange effectivity, which may be modelled either as a constant, or may be computed using the $\epsilon-N T U$ method. When constant, the heat exchange effectivity equals

$$
\epsilon=\text { if } a \text { then } 0.9 \text { else } 0.79 \text {. }
$$

where constants 0.9 and 0.79 are data sheet nominal values and $a$ is a boolean variable that equals true when the evaporative cooling function is enabled and false otherwise.

When using the $\epsilon-N T U$ method, the model from Liu and Allen and Modera (2013) is used, which is implemented using equations (19)-(31). The $\epsilon-N T U$ method is used by default and in 
all validations.

$$
\begin{aligned}
& C_{t o p}=\dot{m}_{d a m R e c T o p} \cdot\left(\text { if } a \text { then } \frac{h_{w b, o u t, t o p}-h_{w b, i n, t o p}}{T_{w b, o u t, t o p}-T_{w b, i n, t o p}} \text { else } c_{p}\right) \\
& h_{w b, \text { out }, \text { top }}=h\left(T_{w b, \text { out }, \text { top }}, X\left(1, T_{w b, \text { out }, \text { top }}\right)\right) \\
& h_{w b, i n, t o p}=h\left(T_{w b, i n, t o p}, X\left(1, T_{w b, i n, t o p}\right)\right) \\
& T_{w b, \text { out }, \text { top }}=T_{w b}\left(T_{\text {out }, \text { top }}, X_{\text {out }, \text { top }}\right) \\
& T_{w b, i n, t o p}=T_{w b}\left(T_{i n, t o p}, X_{i n, t o p}\right) \\
& C_{b o t}=\dot{m}_{\text {damRecBot }} \cdot c_{p} \\
& C_{\text {min }}=\min \left(C_{\text {top }}, C_{\text {bot }}\right) \\
& C_{\text {max }}=\max \left(C_{t o p}, C_{b o t}\right) \\
& C_{r}=\frac{C_{\min }}{C_{\max }} \\
& N T U=\frac{\text { if } a \text { then } U A_{o n} \text { else } U A_{o f f}}{C_{m i n}} \\
& \epsilon_{1 / 2}=1-\exp \left[\frac{\exp \left(-C_{r} \cdot(N T U / 2)^{0.78}\right)-1}{C_{r} \cdot(N T U / 2)^{-0.22}}\right] \\
& \epsilon=\frac{\left[\left(1-\epsilon_{1 / 2} \cdot C_{r}\right) /\left(1-\epsilon_{1 / 2}\right)\right]^{2}-1}{\left[\left(1-\epsilon_{1 / 2} \cdot C_{r}\right) /\left(1-\epsilon_{1 / 2}\right)\right]^{2}-C_{r}} \\
& \dot{Q}_{\text {max }}=C_{\text {min }} \cdot\left[T_{i n, b o t}-T_{w b}\left(T_{i n, t o p}, X_{i n, t o p}\right)\right]
\end{aligned}
$$

where Equation (29) is an approximate formula for a single cross flow heat exchanger from Bergman et al. (2011) with an uncertainty of $3.8 \%$ (Triboix 2009) and Equation (30) is a solution from Kays and London (1984) for two heat exchangers in series where the fluid is mixed between the two passes.

The UA values $U A_{o n}=14000 \mathrm{~W} \mathrm{~K}^{-1}$ and $U A_{o f f}=23000 \mathrm{~W} \mathrm{~K}^{-1}$ were chosen such that the effectivity $\epsilon$, when computed using Equation (30), equals 0.9 and 0.79 for two nominal operating conditions in the manufacturer data sheet where the indirect evaporative cooling function is respectively on and off.

Using these equations and conservation of energy, the two outlet temperatures of the IEH equal:

$$
\begin{aligned}
& T_{\text {out }, \text { top }}=T\left[X_{\text {out }, \text { top }}, \frac{\dot{m}_{\text {damRecTop }} \cdot h_{\text {in }, \text { top }}+\dot{Q}+\dot{m}_{\text {wat }, \text { top }} \cdot h_{\text {wat }}\left(T_{\text {out }, \text { top }}\right)}{\dot{m}_{\text {damRecTop }}+\dot{m}_{w a t, t o p}}\right] \\
& T_{\text {out }, \text { bot }}=T\left[X_{\text {out }, \text { bot }}, \frac{\dot{m}_{\text {damRecBot }} \cdot h_{\text {in,bot }}-\dot{Q}+\dot{m}_{w a t, b o t} \cdot h_{w a t}\left(T_{\text {out }, \text { bot }}\right)}{\dot{m}_{\text {damRecBot }}+\dot{m}_{w a t, b o t}}\right]
\end{aligned}
$$

where $\dot{m}_{w a t, b o t}$ and $\dot{m}_{w a t, t o p}$ are the water mass flow rates that are being added respectively to the bottom and top air streams. The computation of these variables is now elaborated further.

3.2.2.2. Computation of $X_{\text {out,top }}$. Liu and Allen and Modera (2013), or a similar study for cross flow indirect evaporative heat exchangers from Hasan (2012), do not provide an explicit equation for computing the outlet absolute humidity. When the indirect evaporative cooling function is enabled, we therefore assume that the relative humidity at the outlet equals (at least) $80 \%$, which is the outlet 
humidity at nominal operating conditions. The absolute humidity then equals $X\left(0.8, T_{\text {out }}\right.$ top $)$. The return air outlet humidity may however rise above $80 \%$, since when heat is recovered from the return air during winter, it cools down, increasing its relative humidity. The relative humidity can therefore rise above $80 \%$ up to a maximum of the saturation humidity $X\left(1, T_{\text {out }, \text { top }}\right)$. The return air humidity is thus computed using Equation (34).

$$
X_{\text {out }, \text { top }}=\min \left(\left(\text { if } a \text { then } \max \left(X\left(0.8, T_{\text {out }, \text { top }}\right), X_{\text {in }, \text { top }}\right) \text { else } X_{\text {in }, \text { top }}\right), X\left(1, T_{\text {out }, \text { top }}\right)\right) \text {. }
$$

This humidity increase or decrease corresponds to the addition of a water mass flow rate:

$$
\dot{m}_{w a t, t o p}=\dot{m}_{d a m \operatorname{RecTop}} \cdot\left(X_{\text {out }, \text { top }}-X_{\text {in,top }}\right) .
$$

3.2.2.3. Computation of $X_{\text {out,bot }}$. When the indirect evaporative cooling function is enabled, the supply air stream is cooled down by heat transfer through the heat recovery unit. This may cause condensation to occur in the supply air stream, leading to a similar computation.

The supply air stream outlet humidity is therefore computed by Equation (36):

$$
X_{\text {out }, \text { bot }}=\min \left(X_{\text {in }, \text { bot }}, X\left(1, T_{\text {out }, \text { bot }}\right)\right)
$$

where $X_{i n, b o t}$ is the absolute humidity of the supply air inlet. This humidity increase or decrease corresponds to the addition of a water mass flow rate:

$$
\dot{m}_{w a t, b o t}=\dot{m}_{d a m \operatorname{RecBot}} \cdot\left(X_{o u t, b o t}-X_{\text {in }, \text { bot }}\right) .
$$

\subsection{Thermal model active chiller}

The active chiller is split up in a condenser, evaporator and compressor model. The condenser is modelled using a thermal conductor $\mathrm{G}$ such that

$$
\dot{Q}_{c o n}=G_{c o n} \cdot\left(T_{r e f, c o n}-T_{o u t, c o n}\right)
$$

where $T_{r e f, c o n}$ is the temperature of the two-phase refrigerant in the condenser and where $T_{\text {out,con }}$ is the condenser air outlet temperature. $G_{c o n}=24579 \mathrm{~W} \mathrm{~K}^{-1}$ is fit to nominal data sheet values for the variables in Equation (38).

The compressor data sheet (Datasheet 2016) suggests that the refrigerant expansion valve is controlled such that a constant overheating of $10 \mathrm{~K}$ in the evaporator is obtained. Therefore the temperature difference between the evaporator air inlet temperature $T_{i n, e v a}$ and the evaporator twophase refrigerant temperature $T_{r e f, e v a}$ is fixed to the nominal data sheet temperature difference of $10.6 \mathrm{~K}$ such that

$$
T_{\text {ref,eva }}=T_{\text {in }, \text { eva }}-10.6 \text {. }
$$

The chiller cooling power $\dot{Q}_{\text {eva }}$, heating power $\dot{Q}_{c o n}$ and the active power consumption $P_{c o m}$ are modelled using lookup tables $t_{1}(\cdot, \cdot)$ and $t_{2}(\cdot, \cdot)$ such that

$$
\begin{aligned}
& \dot{Q}_{\text {eva }}=\text { if } c \text { then } t_{1}\left(T_{\text {ref,con }}, T_{\text {ref,eva }}\right) \cdot \bmod \text { else } 0 \\
& P_{\text {com }}=\text { if } c \text { then } t_{2}\left(T_{\text {ref,con }}, T_{\text {ref }, \text { eva }}\right) \cdot P L F \text { else } 0 \\
& \dot{Q}_{\text {con }}=\dot{Q}_{\text {eva }}+P_{\text {com }} \\
& P L F=0.1+0.9 \cdot \bmod
\end{aligned}
$$


with $\bmod \in[0,1]$ a modulation input signal, $c$ a boolean representing the status of the compressor and PLF a part load factor based on Bettanini and Gastaldello and Schibuola (2015). The lookup table data was implemented based on the compressor data sheet (Datasheet 2016).

The condenser heats up the return air. Conversely, heat extraction in the evaporator leads to a temperature decrease and may also cause condensation of water vapour. The condensation mass flow rate is determined using the bypass factor (BPF) (Dossat 1981), which is defined as:

$$
B P F=\frac{T_{\text {out }, \text { eva }}-T_{\text {ref,eva }}}{T_{\text {in,eva }}-T_{\text {ref,eva }}}
$$

The BPF can be used to compute the outlet absolute humidity $X_{\text {out,eva }}$ as (Sarkar 2013; Mansour and Khamis and Hassab 2016b; Sarkar 2015):

$$
X_{\text {out }, \text { eva }}=B P F \cdot X_{\text {out }, \text { bot }}+(1-B P F) \cdot \min \left(X\left(1, T_{\text {ref }, \text { con }}\right), X_{\text {out }, \text { bot }}\right) .
$$

Here the $\min (\cdot, \cdot)$ function ensures that condensation only occurs when saturation humidity is reached.

This corresponds to a condensation mass flow rate of

$$
\dot{m}_{w a t, e v a}=\dot{m}_{\text {damRecBot }} \cdot\left(X_{\text {out }, \text { eva }}-X_{\text {out }, \text { bot }}\right) .
$$

The outlet temperature is computed similar to Equation (32).

More detailed evaporator models than the used model exist (Xia et al. 2010; Mansour and Khamis and Hassab 2016b; Mansour and Khamis 2016a; Sarkar 2015; Jeong et al. 2010). However, the added accuracy resulting from using such a model would not necessarily lead to significantly different results, since our model is designed to track a certain evaporator outlet temperature. The heat flow rate is therefore determined by the closed-loop controller and the supply temperature set point of the AHU, and not by the evaporator model. The evaporator model may however affect the $\mathrm{COP}$ and maximum thermal power of the chiller through its effect on the evaporator refrigerant temperature. Moreover, these models require more detailed heat exchanger information, which may not be available.

\subsection{Further equations}

For completeness some trivial equations are listed below.

Since some pressure drop components are connected in parallel, their pressure drops are equal.

$$
\begin{aligned}
\Delta p_{\text {damRecBot }} & =\Delta p_{\text {damBypBot }} \\
\Delta p_{\text {damRecTop }} & =\Delta p_{\text {damBypTop }}
\end{aligned}
$$

Moreover, mass is conserved at fluid junctions, as indicated by Equations (49)-(51). Variable $\dot{m}_{t o p}$ is the total mass flow rate in the top channel before entering the IEH. Variable $\dot{m}_{\text {out,top }}$ is the total mass flow rate in the top channel after leaving the IEH. Variable $\dot{m}_{\text {bot }}$ is the total mass flow 
rate in the bottom channel after leaving the IEH.

$$
\begin{aligned}
\dot{m}_{\text {top }} & =\dot{m}_{\text {damBypTop }}+\dot{m}_{\text {damRecTop }} \\
\dot{m}_{\text {bot }} & =\dot{m}_{\text {fan }, \text { bot }}=\dot{m}_{\text {damBypBot }}+\dot{m}_{\text {damRecBot }}+\dot{m}_{w a t, b o t}+\dot{m}_{\text {wat }, \text { eva }} \\
\dot{m}_{\text {out }, \text { top }} & =\dot{m}_{\text {damBypTop }}+\dot{m}_{\text {damRecTop }}+\dot{m}_{\text {wat }, t o p}
\end{aligned}
$$

The evaporator inlet temperature equals the IEH supply air outlet temperature.

$$
T_{\text {in,eva }}=T_{\text {out }, \text { bot }}
$$

The supply fan outlet temperature is computed assuming perfect mixing occurs between the air flowing through the evaporator and the bypass. In addition waste heat is dumped in the fan air stream such that fan outlet fluid properties of Equations (53) - (55) are found.

$$
\begin{aligned}
h_{f a n, b o t} & =\frac{P_{f a n, b o t}+h\left(X_{\text {out }, e v a}, T_{\text {out }, \text { eva }}\right) \cdot \dot{m}_{\text {damRecBot }}+h_{\text {in }, \text { bot }} \cdot \dot{m}_{\text {damBypBot }}}{\dot{m}_{f a n, b o t}} \\
X_{f a n, b o t} & =\frac{X_{\text {in }, b o t} \cdot \dot{m}_{b o t}+\dot{m}_{w a t, b o t}+\dot{m}_{w a t, e v a}}{\dot{m}_{f a n, b o t}} \\
T_{f a n, b o t} & =T\left(X_{f a n, b o t}, h_{f a n, b o t}\right)
\end{aligned}
$$

\subsection{Control model}

The AHU has seven internal control variables that need to be defined:

- 4 damper positions $y_{i} \in[0,1]$

- $a$, the status of the evaporative cooling (on/off)

- $c$, the status of the compressor (on/off)

- the modulation signal of the compressor $\bmod \in[0,1]$

Since the real control strategy is proprietary, we defined a new control strategy, partly fitted using monitoring data from the AHU. The goal of the control strategy is to track the supply temperature set point $T_{\text {set }}$. Several control options exist that may be used to track this reference.

\subsubsection{Damper control}

The first control option is to operate the four damper positions. To this end a PI controller is used with set point $T_{\text {set }}$ and measurement input $T_{\text {fan }}$. We choose the fan outlet temperature $T_{\text {fan }}$ since fan and motor losses are dissipated into the air stream, causing a temperature rise that needs to be taken into account. The PI controller output $y_{P I}$ is limited to $0 \leq y_{P I} \leq 1$, has an anti wind-up implementation and the integrator time constant is chosen to be $120 \mathrm{~s}$, which is a reasonable order of magnitude based on the observed unit behaviour. Finally, the PI controller gain $k_{P I}$ equals

$$
k_{P I}=\frac{1}{T_{\text {eva,out }}-T_{\text {in }, \text { bot }}},
$$

which ensures that the PI controller takes into account the temperature difference between the two air streams that are mixed. 


\subsubsection{Evaporative and active cooling}

When the supply temperature set point is lower than the supply air inlet temperature and lower than the outlet temperature of the IEH additional cooling needs to be provided. Firstly, the evaporative cooling function is activated. It will only be deactivated when the AHU is switched off or when the supply temperature set point increases above the supply air inlet temperature. If the supply temperature is still too high when the evaporative cooling is on, the compressor will be activated. It will only be deactivated when the AHU is switched off or when the supply air inlet temperature drops below the supply temperature set point $+0.1 \mathrm{~K}$. The offset of $0.1 \mathrm{~K}$ ensures that the cascade is correctly maintained. Mathematically this is expressed as:

$$
\begin{aligned}
& a=o \text { and } T_{\text {set }}<T_{\text {in,bot }} \text { and }\left(\operatorname{pre}(a) \text { or } T_{\text {set }}<T_{\text {in,eva }}\right) \\
& c=o \text { and } a \text { and } T_{\text {set }}<T_{\text {in,eva }} \text { and }\left(\operatorname{pre}(c) \text { or } T_{\text {set }}+0.1<T_{\text {in,eva }}\right)
\end{aligned}
$$

where $T_{i n, b o t}$ is the supply air inlet temperature and pre $(x)$ the value of $x$ during previous time step.

When the compressor is enabled, a second PI controller determines the modulation factor $0 \leq$ $\bmod \leq 1$ such that the temperature $T_{\text {set }}$ is obtained at the fan outlet temperature $T_{\text {fan }}$.

Finally, four expressions determine the valve openings $y_{\text {damBypTop }}, y_{\text {damRecTop }}, y_{\text {damRecBot }}$ and $y_{\text {damBypBot }}$. Equations (60) - (63) were deduced from measurement data.

$$
\begin{aligned}
& y_{\text {damBypTop }}=\text { if } o \text { and not } a \text { and not } c \text { then } 1-y_{P I} \text { else } 0 \\
& y_{\text {damRecTop }}=\text { if } o \text { then } 1 \text { else } 0 \\
& y_{\text {damRecBot }}=\text { if } o \text { then (if } c \text { then } 1 \text { else } \min \left(2 \cdot y_{P I}, 1\right) \text { ) else } 0 \\
& y_{\text {damBypBot }}=\text { if } o \text { then (if } c \text { then } 0 \text { else } \min \left(2-2 \cdot y_{P I}, 1\right) \text { ) else } 0
\end{aligned}
$$

\subsection{Electrical power consumption}

The active electrical power consumption of the AHU consists of

- the zero-load power consumption $P_{0}$,

- the two fan power consumptions $P_{f a n, t o p}$ and $P_{f a n, b o t}$,

- the evaporative cooling circulation pump power consumption $P_{\text {pum }}$,

- the compressor power consumption $P_{\text {com }}$.

Reactive power is not modelled.

The computations of $P_{f a n}$ and $P_{\text {com }}$ were already discussed. $P_{\text {pum }}$ was chosen equal to the data sheet value of $770 \mathrm{~W}$. Using electrical power consumption measurements the stand-by power consumption $P_{0}$ was found to be $150 \mathrm{~W}$ when the unit is off. According to the manufacturer, typically $75 \mathrm{~W}$ is consumed by the compressor crankcase heater when the compressor is off, which accounts for half of the AHU stand-by power consumption. When the unit is on, the zero load power consumption was estimated by performing an experiment where $\Delta p_{\text {set }}=50 \mathrm{~Pa}$ such that the fan power consumption was as low as possible. The fan power consumption was then computed using the measured mass flow rates, measured damper positions and the pressure drop model. The difference between the measured and simulated electrical power was found to be $630 \mathrm{~W}$. Based on the data sheet the electrical drive losses at $20 \%$ nominal load are $375 \mathrm{~W}$ per drive. A large fraction of this $630 \mathrm{~W}$ may therefore be the zero load power consumption of the electrical drives. 
The total power consumption $P_{e l}$ is therefore defined as

$$
\begin{aligned}
P_{e l} & =P_{0}+P_{\text {fan }, \text { bot }}+P_{\text {fan }, \text { top }}+P_{\text {pum }}+P_{\text {com }} \\
P_{0} & =\text { if } o \text { then } 150+630 \text { else } 150 \\
P_{\text {pum }} & =\text { if } a \text { then } 770 \text { else } 0
\end{aligned}
$$

\section{Implementation details}

Section 3 describes the physical principles that were used to model the AHU. This section discusses numerical aspects of the model that ensure the model is fast and robust.

Firstly we discuss the dynamics of the AHU model since these can be a limiting factor for the simulation speed (Jorissen and Wetter and Helsen 2015). Regularisations and the used air model are discussed afterwards.

\subsection{Model dynamics}

Except for the PI controller we did not discuss any model dynamics, i.e. all equations are steady state. If these equations would be solved directly, the Modelica solver would generate a large nonlinear algebraic loop, which may be difficult to solve.

The physically modelled system however contains dynamics that may be used to decouple the algebraic loops into smaller parts. The disadvantage is that these states may introduce small time constants, which may result in increased solver time if this leads to a larger number of simulation steps.

The following variables are therefore time-dependent states by default:

(1) $T_{\text {out }, \text { top }}$ and $T_{\text {out }, \text { bot }}$

(2) $T_{\text {out }, \text { eva }}, T_{\text {out }, \text { con }}$ and $T_{\text {ref,con }}$

(3) the temperature measurement of $T_{f a n}$, i.e. the input of the damper PI controller

Model dynamics for variable $T_{i}$ are implemented by adding new state variable $T_{i}^{\prime}$, which is computed using Equation (67).

$$
\frac{\mathrm{d} T_{i}^{\prime}}{\mathrm{d} t}=\frac{T_{i}-T_{i}^{\prime}}{\tau_{n o m} \frac{\dot{m}_{\text {nom }}}{\dot{m}}}
$$

In all equations $T_{i}$ is then replaced by $T_{i}^{\prime}$, except for the equation that determines $T_{i}$. Consider for instance the case where $T_{i}=T_{\text {out,top }}$, then in all equations except in the left hand side of Equation (32), $T_{\text {out,top }}$ is replaced by $T_{\text {out,top }}^{\prime}$. In Equation (67) $\tau$ is a user-defined time constant that is set to one minute by default.

This value is chosen to ensure that the control loop is stable and to avoid short time constants that may increase simulation time when using explicit time integration algorithms. Its numerical value should therefore not be interpreted physically, although Equation (67) may be interpreted as the dynamics of a perfectly mixed volume with mass $\dot{m}_{n o m} \cdot \tau_{n o m}$. For the slowly changing boundary conditions that typically occur in building simulations, the model will be in steady state and therefore the value of these time constants should not affect the model results.

Note also that when water is injected in the heat exchanger, then this mass flow rate is not added to the total outlet mass flow rate. The last two terms in Equation (50) and the last term in Equation (51) are therefore neglected. This is because mass dynamics are steady state, and a change in water condensation mass flow rate would therefore immediately affect the outlet mass flow rate. An increase in outlet mass flow rate typically results in a higher pressure drop and would 
therefore reduce the inlet mass flow rate, which in turn affects the thermal dynamics, which affects the computation of the water condensation mass flow rate. This leads thus to an algebraic loop that couples the thermal and mass dynamics, which needs to be avoided (Jorissen and Wetter and Helsen 2015).

Dynamics of fans and dampers, valves are neglected. Due to the added thermal dynamics, Equation (59) is changed to include an 'on delay' of $5 \tau$. This gives the system, which has a time constant $\tau$, sufficient time to react when enabling the evaporative cooling, before enabling the compressor.

\subsection{Regularisations}

A second important aspect is the robustness of the model. All equations should be defined such that they can be solved reliably. Consider for instance the formulation of Equation (44). This formulation of the numerator can lead to a division by zero when $T_{i n, e v a}=T_{\text {ref,eva }}$. Therefore we regularise several equations using functions such as the inverseXRegularized(x) from the Annex 60 library (Wetter et al. 2015), which outputs a smooth approximation of $1 / x$ around $x=0$.

\subsection{Air model}

By default the moist air medium Annex60.Media.Air from the Annex60 library (Wetter et al. $2015)$ is used. This medium assumes instead of the ideal gas law

$$
p \cdot v=r \cdot T
$$

that

$$
p \cdot v=c t e
$$

and further assumes that the gas properties are temperature-independent. Modelica however provides the option to choose a different medium model.

\section{Calibration}

Most model parameters were defined earlier using data sheet information. The only variables that are undefined up to this point are:

- $\Delta p_{f o u, f 12}$ and $\Delta p_{f o u, f 3}$, the degree of filter fouling,

- $\alpha$, the fraction of the dynamic pressure that can be recovered in the bypass,

- $k_{1}$, the ratio of the static pressure drop of a fully opened damper over the dynamic pressure.

These parameters were calibrated using measurement data of the electrical power consumption $P_{e l}$ and assuming that $\Delta p_{\text {fou, f12 }}=\Delta p_{\text {fou, } f 3}$. The calibration result is shown in Figure 4 . Note that periods $0-12 \mathrm{~h}, 20-58 \mathrm{~h}$ and $90-105 \mathrm{~h}$ are the most relevant since only then the compressor $c$ and evaporative cooling $a$ are disabled and therefore cannot introduce additional errors in the power computation. The measured electrical power consumption is indicated using thick blue lines.

Simulations were run using the Modelica simulation tool Dymola 2017.

Parameters $\Delta p_{\text {fou,f12 }}$ and $\Delta p_{\text {fou,f3 }}$

At hour 75 the unit was shut down and the filters were replaced, such that we can expect to find $\Delta p_{\text {fou }, f 12}=\Delta p_{\text {fou }, f 3}=0 \mathrm{~Pa}$ starting from this point in time. The best results are however obtained 
for $\Delta p=110 \mathrm{~Pa}$, which suggests that not all filters were replaced, or there are additional pressure drops that are not taken into account by the present model. For instance the supply inlet and return outlet duct and vent, and the dynamic pressure drop between the AHU and the environment were not modelled.

Before the filter replacement the simulation results are in good agreement with the measurements when the nominal pressure drops of the filters equal $200 \mathrm{~Pa}$. For this simulation $\alpha=0.5$ and $k_{1}=0.45$ were used.

\section{Parameter $\alpha$}

The dynamic pressure recovery factor $\alpha$ should be between 0 and 1. Based on Figure 4 an intermediate value of 0.5 is found. For this simulation $\Delta p_{f o u, f 12}=\Delta p_{\text {fou, f3 }}=200 \mathrm{~Pa}$ and $k_{1}=0.45$ were used. Hours 60-120 should be disregarded on the Figure since the simulation does not take into account the filter replacement.

\section{Parameter $k_{1}$}

The results of Figure 4 are not very sensitive to the value of $k_{1}$, but a value of $\sim 0.45$ gives good overall results. This value is also suggested by (Haves and DeSimone and Mei 1996; Wetter et al. 2014). For this simulation $\Delta p_{f o u, f 12}=\Delta p_{f o u, f 3}=200 \mathrm{~Pa}$ and $\alpha=0.5$ were used. Hours $60-120$ should be disregarded on the Figure since the simulation does not take into account the filter replacement.

For the validations (Section 6) a similar calibration has been performed to remove any offset in the electrical power consumption that is caused by the fouling of filters. Furthermore $\alpha=0.5$ and $k_{1}=0.45$ are used for all validations.

\section{Validation}

Several validations were performed. The first validation checks whether the nominal data sheet performance data are obtained. The second validation checks whether the nominal performance of the indirect evaporative heat exchanger, combined with the active chiller is obtained. The third validation checks how well the AHU outlet temperatures and electrical power consumption correspond to measurement data when the measured control signals are used during a cold period when the cooling functions are disabled. The fourth validation is the same as the third, but for a data set containing periods where active cooling is enabled. The fifth validation checks how well the electrical power consumption and control signals correspond to measurement data when the model control strategy is used.

\subsection{Nominal performance data}

\subsubsection{Validation one}

For the first validation the indirect evaporative heat exchanger inlet conditions are fixed to the data sheet inlet conditions in Table 3. The evaporative cooling function is respectively enabled and disabled for the summer and winter operating points.

Table 4 compares the steady state simulation results of the outlet temperatures and relative humidities with the data sheet values. The results match the data sheet specifications well, with temperature and humidity errors in the order of $0.3 \mathrm{~K}$ and $1 \%$. 

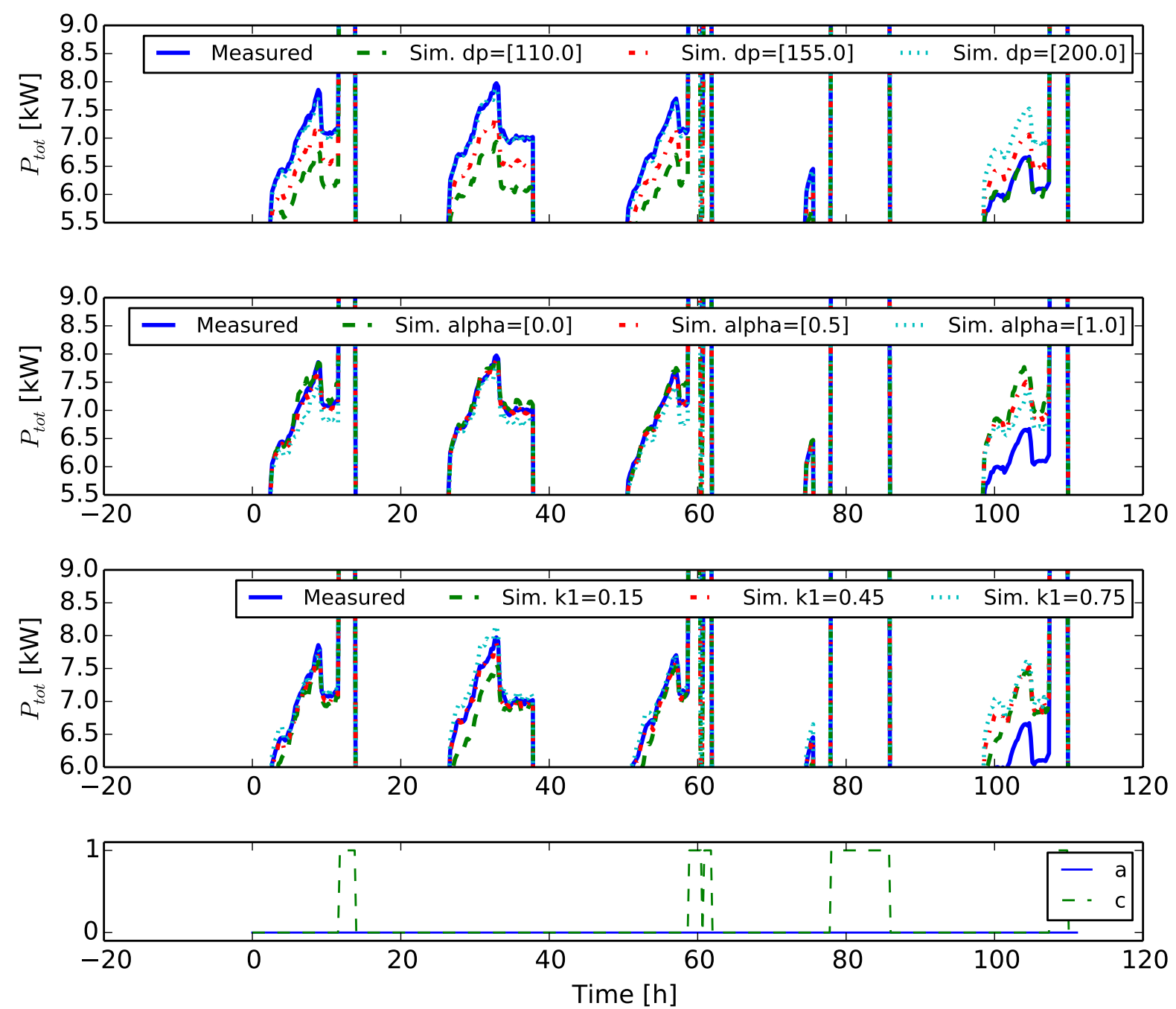

Figure 4.: Calibration of $d p=\Delta p_{f o u, f 12}=\Delta p_{f o u, f 3}, \alpha$ and $k_{1}$. The measured electrical power consumption is indicated with a thick blue line. The other lines indicate the simulated electrical power consumption when the simulation uses the variable value indicated in the legend. At hour 30 the unit was disabled and the filters were replaced. The bottom graph indicates the status of the evaporative cooling and compressor, respectively denoted by $a$ and $c$.

Table 3.: Nominal data sheet inlet conditions of the indirect evaporative heat exchanger, the condenser and the evaporator.

\begin{tabular}{lrrr}
\hline & Vol. flow rate $\left[\mathrm{m}^{3} h^{-1}\right]$ & Temperature $\left[{ }^{\circ} \mathrm{C}\right]$ & Rel. Hum. [\%] \\
\hline Supply air inlet summer & 14493 & 32 & 40 \\
Return air inlet summer & 14200 & 26.4 & 54 \\
\hline Supply air inlet winter & 12460 & -12 & 90 \\
Return air inlet winter & 14200 & 22.4 & 39 \\
\hline
\end{tabular}

5.5 
Table 4.: Comparison of data sheet outlet data (subscript data) and simulation results (subscript sim) for indirect evaporative heat exchanger, condenser and evaporator.

\begin{tabular}{l|rr|rr}
\hline & \multicolumn{4}{|c}{} \\
& $T_{\text {data }}\left[{ }^{\circ} \mathrm{C}\right]$ & $T_{\text {sim }}\left[{ }^{\circ} \mathrm{C}\right]$ & $\phi_{\text {data }}[\%]$ & $\phi_{\text {sim }}[\%]$ \\
\hline Supply air outlet summer & 21.4 & 21.06 & 75 & 76.2 \\
Return air outlet summer & 25.3 & 25.65 & 80 & 80.0 \\
\hline Supply air outlet winter & 15.1 & 15.15 & 13 & 11.4 \\
Return air outlet winter & 1.2 & 1.32 & 100 & 100 \\
\hline Condenser outlet & 35.2 & 35.11 & $/$ & $/$ \\
Evaporator outlet & 16.7 & 17.09 & 87 & 85.6 \\
\hline
\end{tabular}

\subsubsection{Validation two}

The second validation performs a similar comparison for the condenser and evaporator when the active chiller is enabled. The results are obtained by simulating the active chiller without the heat recovery unit. The inlet conditions are therefore the outlet conditions of the indirect evaporative heat exchanger during summer conditions in Table 4. The results at the bottom of Table 4 show small errors. Note that the BPF model condenses more water from the air stream in the evaporator than in reality. This may explain the higher evaporator outlet temperature since less cooling power is available for sensible cooling.

\subsection{Measurement data}

The third and fourth validations compare the AHU model with measurement data during operation. Measured variables are

- the two inlet temperatures and relative humidities,

- the volumetric flow rates of the fans,

- the supply and return duct static pressures relative to the ambient pressure,

- the supply air temperature and relative humidity,

- the apparent electrical power and power factor,

- the four valve positions,

- variables $a$ and $c$.

The type and accuracy of the used sensors is unknown. The measurement data is averaged out over two minute intervals.

For these validations we apply the measured control signals of the valves positions, $a$ and $c$. Since the real modulation signal mod is not logged, the simulation model's integrated controller determines its value.

\subsubsection{Validation three}

Figure 5 compares the measured electrical power consumption with the simulation model for a data set when the compressor and indirect evaporative cooling are off. The bottom three subgraphs plot the boundary conditions of the AHU. The figure shows good agreement between the measured and the simulated electrical power consumption, with a mean absolute error of $106 \mathrm{~W}$, which is a relative error of $1.2 \%$ when compared to the peak power of $9.1 \mathrm{~kW}$. The largest error occurs during the last day, during periods when both bypass valves are partly opened. Even sudden drops in the supply pressure and flow rates are correctly simulated. The impact of changes in damper positions is also modelled accurately. 

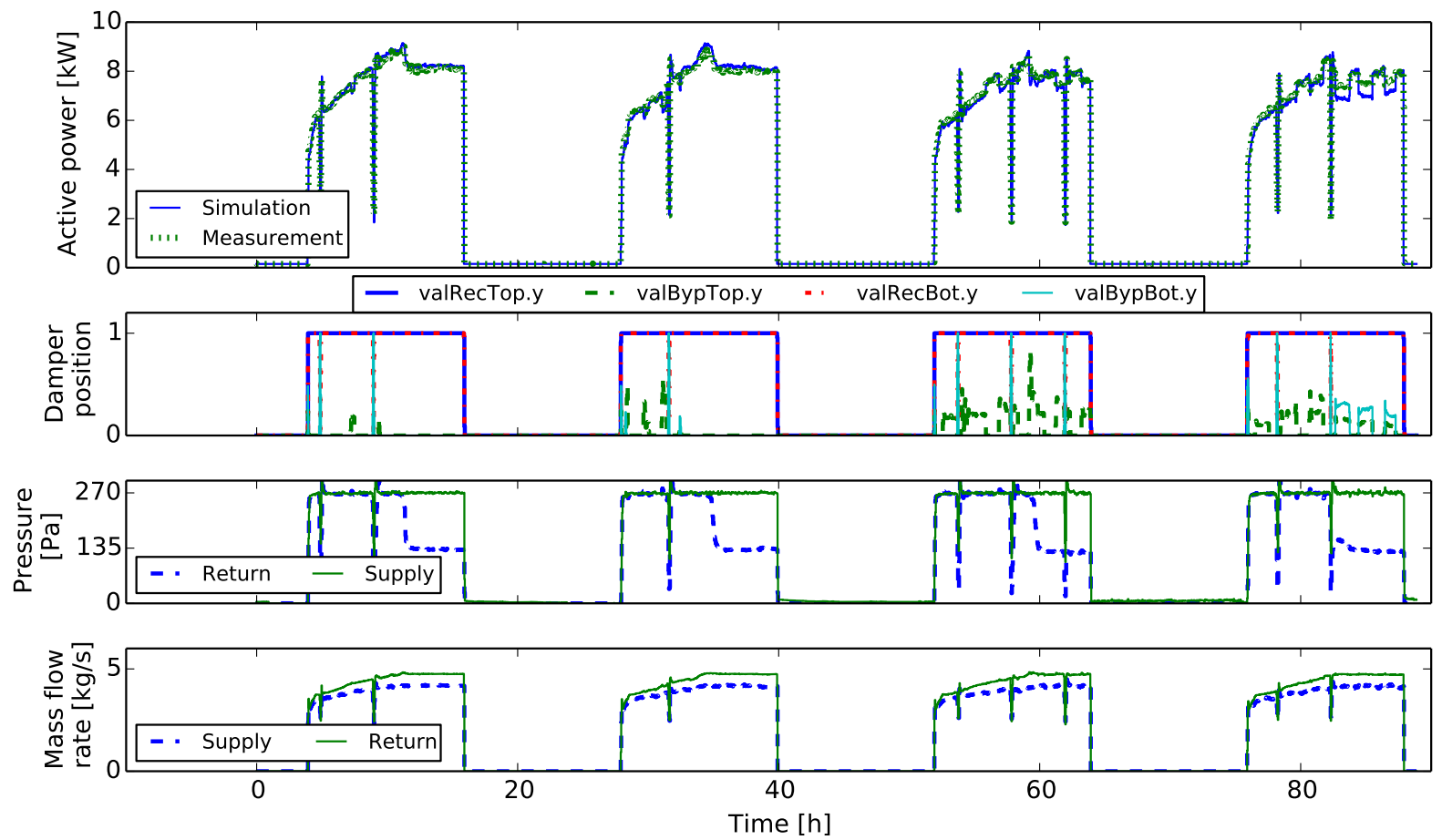

Figure 5.: Validation of electrical power consumption from fans for the boundary conditions displayed on the bottom 3 graphs and indirect evaporative and active cooling disabled.

\subsubsection{Validation four}

Figure 6 shows a similar comparison during spring, when the indirect evaporative and active cooling function are enabled occasionally, leading to larger power consumptions and new sources of model errors. The figure (1st plot) shows a difference between the measured and simulated electrical power with an average absolute error of $181 \mathrm{~W}$ compared to a peak power of $16 \mathrm{~kW}(1.1 \%)$.

The largest errors occur when using the chiller and indirect evaporative cooling simultaneously. This is probably caused by an error in the evaporative cooling power computation, since these errors need to be compensated by the chiller if the supply temperature set point is to be obtained. Menerga ${ }^{\mathrm{TM}}$ confirms that the outlet humidity and therefore also the evaporative cooling power depends on the inlet conditions. Therefore the assumption that the outlet humidity is at least $80 \%$ is inaccurate, probably causing this error. However, more accurate information is not available.

Figure 6 (2nd plot) also shows a comparison between the measured and the simulated outlet temperatures. The reader should only look at periods where the chiller is disabled, since otherwise the chiller's controller will track the supply temperature set point. For other periods all control variables are read from measurement data, meaning no feedback is applied. Still, the simulated outlet temperature closely matches the measured outlet temperature, suggesting that the model is accurate.

\subsubsection{Validation five}

The fifth validation uses the same data set as the fourth validation, but uses the internal control strategy instead of measured control variables. The results of this simulation are again compared to measurements.

Figure 7 shows large differences in the electrical power consumption. The reason for this is that the model control strategy operates the unit more efficiently, i.e. it better chooses between evaporative and active cooling. For instance, at hour 5 the compressor is activated in the measurement data, 

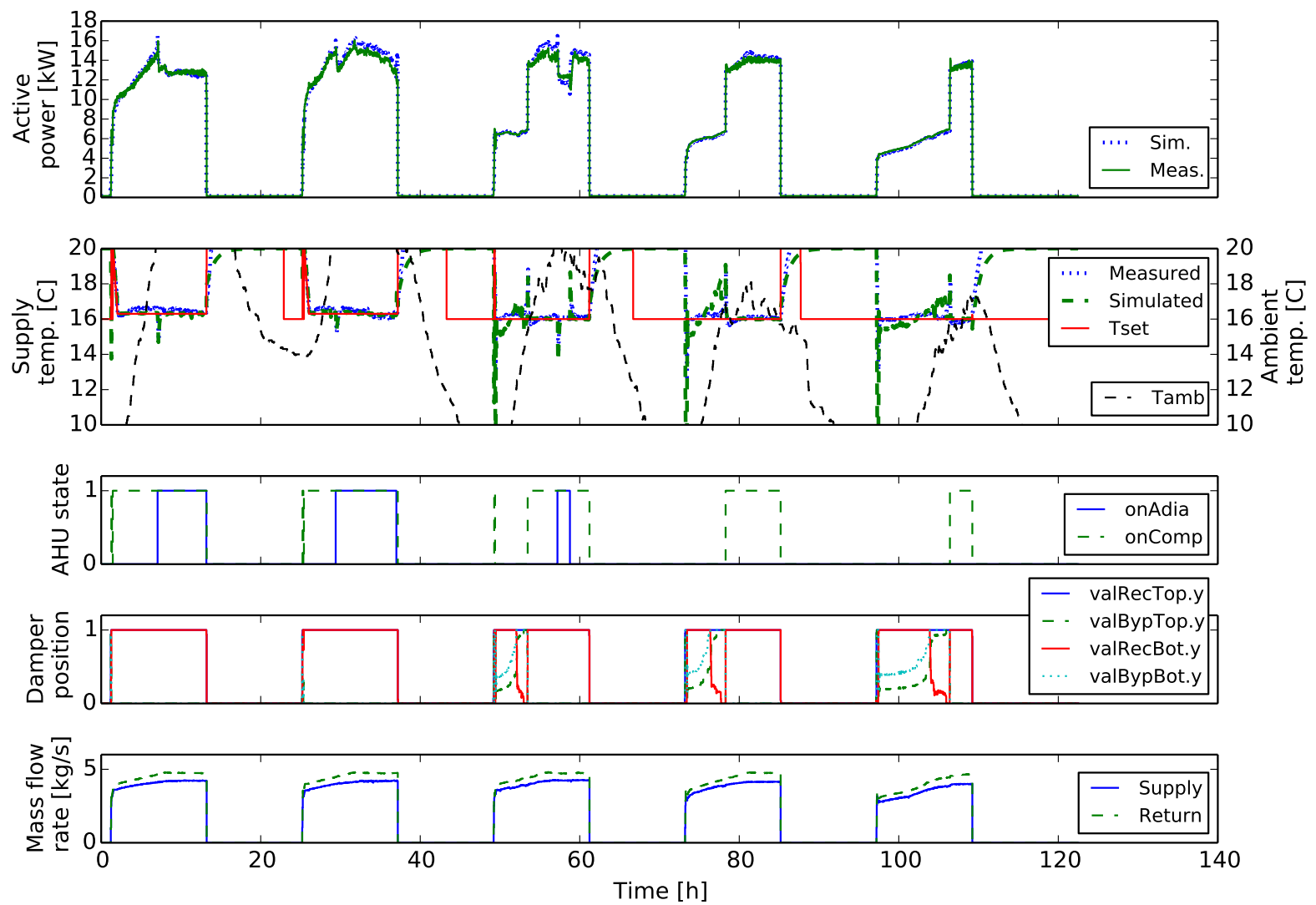

Figure 6.: Validation of electrical power consumption from fans for the boundary conditions displayed on the bottom 3 graphs when indirect evaporative and active cooling are used.

while the ambient temperature is still well below the supply temperature set point. Therefore free cooling can be used. Menerga ${ }^{\mathrm{TM}}$ attributes this effect to the thermal inertia when starting up the unit, causing the unit to measure higher temperatures. The measurements also show that the active cooler is occasionally activated while the indirect evaporative cooling is off.

The set point temperature is well tracked by both the measurements and the simulation.

When dampers are used to control the outlet temperature, i.e. when the chiller is off, the damper positions show a very similar trend. This suggests that the damper characteristics of the model and the flow-dependent effectiveness-NTU method are accurate.

\section{Conclusion}

This paper describes, calibrates and validates the model of an air handling unit that allows free cooling, indirect evaporative cooling and active cooling. Furthermore the model contains a bypass function and an integrated controller. Since the real control strategy is proprietary, a custom controller was implemented. The model uses physical principles and data sheet information. Only few parameters needed to be calibrated using measurement data. Average absolute errors of the electrical power consumption are in the order of $1 \%$. Based on the simulation results, the newly developed controller performs better than the real controller implementation. The model is published open-source in the IDEAS Modelica library (Baetens et al. 2015). The model or its submodels may be used as templates or examples for the development of other models, including but not limited to air handling units. 

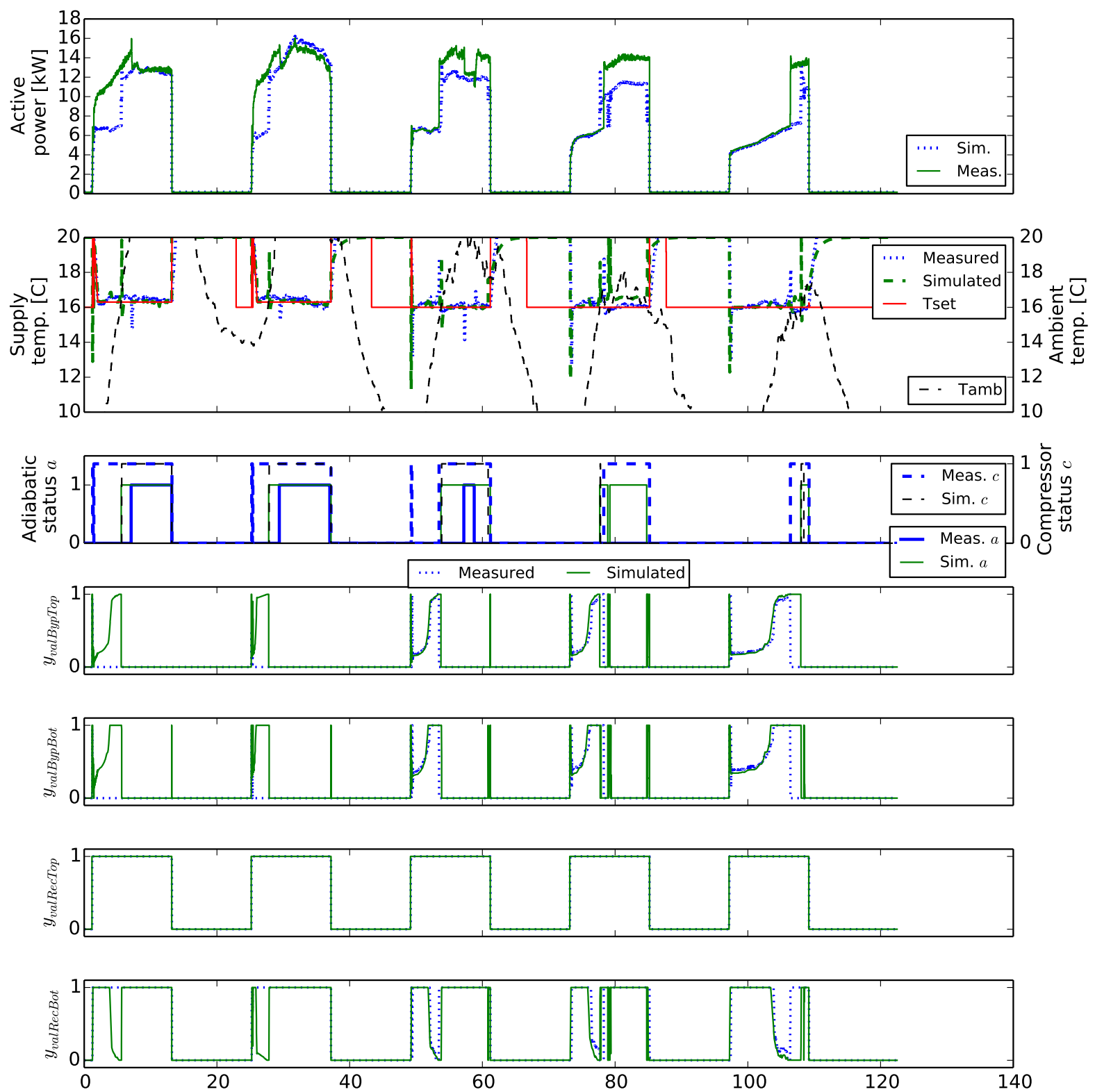

Figure 7.: Comparison of the measured performance of the real controller and the simulated performance when using the new controller. Results show lower energy use when applying the new controller and good agreement of the (closed-loop) damper positions.

This work further demonstrates Modelica as a suitable language for simulating complex HVAC models. HVAC or Building libraries such as the Annex 60 (Wetter et al. 2015), IDEAS (Baetens et al. 2015) and Buildings (Wetter et al. 2014) should be developed further by researchers or even manufacturers to provide a broader coverage of the typically used HVAC components. A switch to Modelica would then allow detailed and accurate HVAC or even whole building or district simulations and gradient based optimisations. 


\section{Acknowledgements}

The authors thank Menerga ${ }^{\mathrm{TM}} \mathrm{NV}$ Belgium and in particular Johan Verplaetsen for their open attitude when sharing information that made the development of this paper possible. We also thank Schuler Sàrl for sharing the building measurement data that was used in this validation. This work emerged from the Annex 60 project, an international project conducted under the umbrella of the International Energy Agency (IEA) within the Energy in Buildings and Communities (EBC) Programme. Annex 60 develops and demonstrates new generation computational tools for building and community energy systems based on Modelica, Functional Mockup Interface and BIM standards.

\section{Funding}

This work was supported by the Agency for Innovation by Science and Technology in Flanders (IWT) under Grant 131012.

\section{References}

ASHRAE Handbook: Fundamentals 2009. Atlanta: American Society of Heating, Refrigerating and Air Conditioning Engineers

Baetens, Ruben, Roel De Coninck, Filip Jorissen, Damien Picard, Lieve Helsen and Dirk Saelens. 2015. "OPENIDEAS - An Open Framework for Integrated District Energy Simulations." In Building Simulation 2015, edited by Jyotirmay Mathur and Vishal Garg, 347-354, IBPSA.

Bergman, T.L., F.P. Incropera, D.P. DeWitt and A.S. Lavine. 2011. Fundamentals of Heat and Mass Transfer. New York: Wiley

Bettanini, Ernesto, Alessio Gastaldello and Luigi Schibuola. 2003. "Simplified models to simulate part load performances of air conditioning equipments" In Building Simulation 2003, 107-114.

Drawley, Drury B., Linda K. Lawrie, Frederick C. Winkelmann, W.F. Buhl, Y. Joe Huang, Curtis O. Pedersen, Richard K. Strand, et al. 2001. "EnergyPlus: creating a new-generation building energy simulation program." Energy and Buildings 33:319-331. doi:10.1016/S0378-7788(00)00114-6

EnergyPlus Version 8.5 Documentation - Engineering Reference. 2016.

Dossat, R.J. 1981. Principles of Refrigeration. New York: Wiley

Hasan, Ala. 2012. "Going below the wet-bulb temperature by indirect evaporative cooling: Analysis using a modified $\epsilon$-NTU method" Applied Energy 89(1):237-245. doi:10.1016/j.apenergy.2011.07.005

Haves, P., L.K. Norford, M. DeSimone and L. Mei A standard simulation testbed for the evaluation of control algorithms and strategies, rp-825 final report Atlanta: American Society of Heating, Refrigerating and Air Conditioning Engineers

"Hermetic scroll compressors - digital: ZRD125KCE-TFD" Elektronika S.A.. Accessed 21 June 2016 http://www.elektronika-sa.com.pl/tcmodelpdf.php?MID=88175\&RID $=4$

Jeong, Kwangkook, Michael J. Kessen, Harun Bilirgen and Edward K. Levy. 2010. "Analytical modeling of water condensation in condensing heat exchanger" International Journal of Heat and Mass Transfer 53(11-12):2361-2368. doi:10.1016/j.ijheatmasstransfer.2010.02.004

Jorissen, Filip, Michael Wetter and Lieve Helsen. 2015. "Simulation Speed Analysis and Improvements of Modelica Models for Building Energy Simulation" In Proceedings of the 11th International Modelica Conference, edited by Peter Fritzson and Hilding Elmqvist, 56-59, Linköping: Modelica Association.

Kays, Willian Morrow and Alexander Louis London. 1984. Compact heat exchangers New York: McGraw-Hill

Klein, A. Sanford. 2010. "TRNSYS 17, A Transient System Simulation Program." Solar Energy Laboratory. Madison : University of Wisconsin

Legg, R.C. 1986. "Characteristics of single and multi-blade dampers for ducted air systems" Building Services Engineering Research \&3 Technology 7(4):129-145. doi:10.1177/014362448600700402

Li, Pengfei, Hongtao Qiao, Yaoyu Li, John E. Seem, Jon Winkler and Xiao Li. 2014 "Recent advances in dynamic modeling of HVAC equipment. Part 1: Equipment modeling." HVACERR Research 20(1):136-149. doi:10.1080/10789669.2013.836877 
Li, Shun and Jin Wen. 2010. "Development and validation of a dynamic air handling unit model, Part 1." ASHRAE Transactions 116(1):45-56.

Liu, Zhijun, William Allen and Mark Modera. 2013. "Simplified thermal modeling of indirect evaporative heat exchangers" HVACER Research 19(3):257-267. doi:10.1080/10789669.2013.763653

Mansour, M. Khamis. 2016. "Practical effectiveness-NTU model for cooling and dehumidifying coil with non-unit Lewis Factor" Applied Thermal Engineering 100:1111-1118. doi:10.1016/j.applthermaleng.2016.02.096

Mansour, M. Khamis and M. A. Hassab. 2016. "Novel lumped modeling for determining thermal performance of DX evaporator under partially-wet and fully-wet conditions" Applied Thermal Engineering 98:1025-1035. doi:10.1016/j.applthermaleng.2015.12.094

Nassif, Nabil, Samir Moujaes, and Mohammed Zaheeruddin. 2008. "Self-tuning dynamic models of HVAC system components." Energy and Buildings 40(9):1709-1720. doi:10.1016/j.enbuild.2008.02.026

Pérez-Lombard, Luis and José Ortiz and Christine Pout. 2008. "A review on buildings energy consumption information." Energy and Buildings 40(3):394-398. doi:10.1016/j.enbuild.2007.03.007

Sarkar, Mridul. 2015. "Simplified thermodynamic modeling of chilled water coils based on bypass factors" Energy and Buildings 103:384-395. doi:10.1016/j.enbuild.2015.06.066

Sarkar, Mridul. 2013. "Theoretical comparison of cooling loads of an air handling unit in blow-through and draw-through configurations." Energy and Buildings 64:239-248. doi:10.1016/j.enbuild.2013.04.025

Späth, Helmuth. 1995. One Dimensional Spline Interpolation Algorithms. Natick: A K Peters Ltd.

Triboix, Alain. 2009. "Exact and approximate formulas for cross flow heat exchangers with unmixed fluids." International Communications in Heat and Mass Transfer 36(2):121-124. doi:10.1016/j.icheatmasstransfer.2008.10.012

Wetter, Michael. 2013. "Fan And Pump Model That Has A Unique Solution For Any Boundary Condition And Control Signal." In Building Simulation 2013, edited by Etienne Wurtz, 3505-3512, IBPSA.

Wetter, Michael, Wangda Zuo, Thierry S. Nouidui and Xiufeng Pang. 2014. "Modelica buildings library" Journal of Building Performance Simulation 7(4):253-270. doi:10.1080/19401493.2013.765506

Wetter, Michael, Marcus Fuchs, Pavel Grozman, Lieve Helsen, Filip Jorissen, Moritz Lauster, Müller Dirk et al. 2015. "IEA EBC Annex 60 Modelica Library - An International Collaboration to Develop a Free Open-Source Modelica Library for Buildings and Community Energy Systems" In Building Simulation 2015, edited by Jyotirmay Mathur and Vishal Garg, 396-402, IBPSA.

Xia, Liang, M. Y. Chan, S. M. Deng, and X. G. Xu. 2014. "Analytical solutions for evaluating the thermal performances of wet air cooling coils under both unit and non-unit Lewis Factors." Energy Conversion and Management 51(10):2079-2086. doi:10.1016/j.enconman.2010.02.041 